\title{
Self-other control: a candidate mechanism for social cognitive function
}

\section{Sophie Sowden* and Punit Shah}

MRC Social, Genetic and Developmental Psychiatry Centre, Institute of Psychiatry, Psychology and Neuroscience, King's College London, UK

${ }^{*}$ Correspondence: sophie.sowden@kcl.ac.uk

Edited by:

James W. Moore, Goldsmiths, University of London, UK

Reviewed by:

Jennifer Louise Cook, University College London, UK

Keywords: self-other control, social cognition, autism, schizophrenia, right temporoparietal junction, neuropsychological markers

Despite ever-growing interest in the "social brain" and the search for the neural underpinnings of social cognition, we are yet to fully understand the basic neurocognitive mechanisms underlying complex social behaviors. One such candidate mechanism is the control of neural representations of the self and of other people (Brass et al., 2009; Spengler et al., 2009a), and it is likely that "common" disorders of social cognition such as autism and schizophrenia involve atypical modulation of self and other representations (Cook and Bird, 2012; Ferri et al., 2012). This opinion piece will first consider self-other control as a possible low-level neurocognitive mechanism for social functioning across many domains of social cognition. Neuroscientific evidence will be drawn upon and the potential for a better understanding and identification of neuropsychological markers for atypical social cognitive development, discussed.

\section{A CANDIDATE MECHANISM}

Humans are uniquely social beings and therefore identifying commonalities in the mechanisms recruited across various domains of social cognition is important, providing an understanding not only of typical social cognitive function but also what happens when this goes wrong. A candidate process which may be recruited across a range of socio-cognitive tasks is the ability to hold in mind and manage neural representations of both the self and of other people. Motor representations pertaining to the self and of the other are necessary in the case of imitation (di Pellegrino et al., 1992; Gallese et al.,
1996), and self and other representations of mental and affective states are necessary for theory of mind and empathy, respectively (Decety and Grèzes, 2006; Brass and Spengler, 2008; Iacoboni, 2009). Within each of these domains of social cognition a form of "contagion" can be observed where information is shared between representations of the self and other. In the case of action observation, individuals automatically and often non-consciously imitate the actions of those with whom they interact (Chartrand and Bargh, 1999; Brass et al., 2000; Heyes, 2011).

Social interaction therefore appears to be facilitated by a shared representational system. However, social situations sometimes require an individual to distance themselves from other people and in other instances require one to engage more with representations of others. For example, when taking another's perspective, engaging a successful theory of mind, or empathizing with others it is important to put aside or inhibit one's own perspective, mental or affective state and enhance that of the interacting other. Conversely, in order to control the tendency to imitate others' actions and generate our own independent actions, we must inhibit the motor representation pertaining to the interacting other and activate the motor representation for our own intended action. Differing requirements to inhibit or enhance representation of the self or the other for successful social interaction highlights the crucial role played by the ability to control or switch between neural representations attributed to the self and to other people, hereafter referred to as "self-other control" (Decety and
Sommerville, 2003; Brass and Heyes, 2005; Spengler et al., 2009a).

A task now readily used as a behavioral index of self-other control is that of the control of imitation (Figure 1; Brass et al., 2001, 2005, 2009; Spengler et al., 2009a; Catmur and Heyes, 2011; Santiesteban et al., 2012a,b; Sowden and Catmur, 2013). The task requires participants to inhibit imitative response tendencies, and therefore provides an index of an individual's ability to enhance the self-representation whilst inhibiting the other-representation. Additionally, Obhi and Hogeveen (2013) have proposed a complimentary task whereby performance under the opposite control requirements can be investigated; inhibiting the self-representation whilst exciting the other-representation. In combination, these tasks provide a neat index of control, the ability to supress not only representations of the other but also of the self.

Despite the very different higher-level cognitive processes involved in a wide range of social cognitive abilities, a series of behavioral findings in neurotypical adults support the existence of a common low-level mechanism of self-other control. Performance in one social domain such as the control of imitation correlates highly with performance in other social domains requiring self-other control. These include perspective-taking, theory of mind and empathy (Spengler et al., 2010a), and remain even when controlling for more general executive functioning processes (e.g., Spengler et al., 2010b). The link between performance on different tasks requiring self-other control is not merely correlational; training to inhibit 


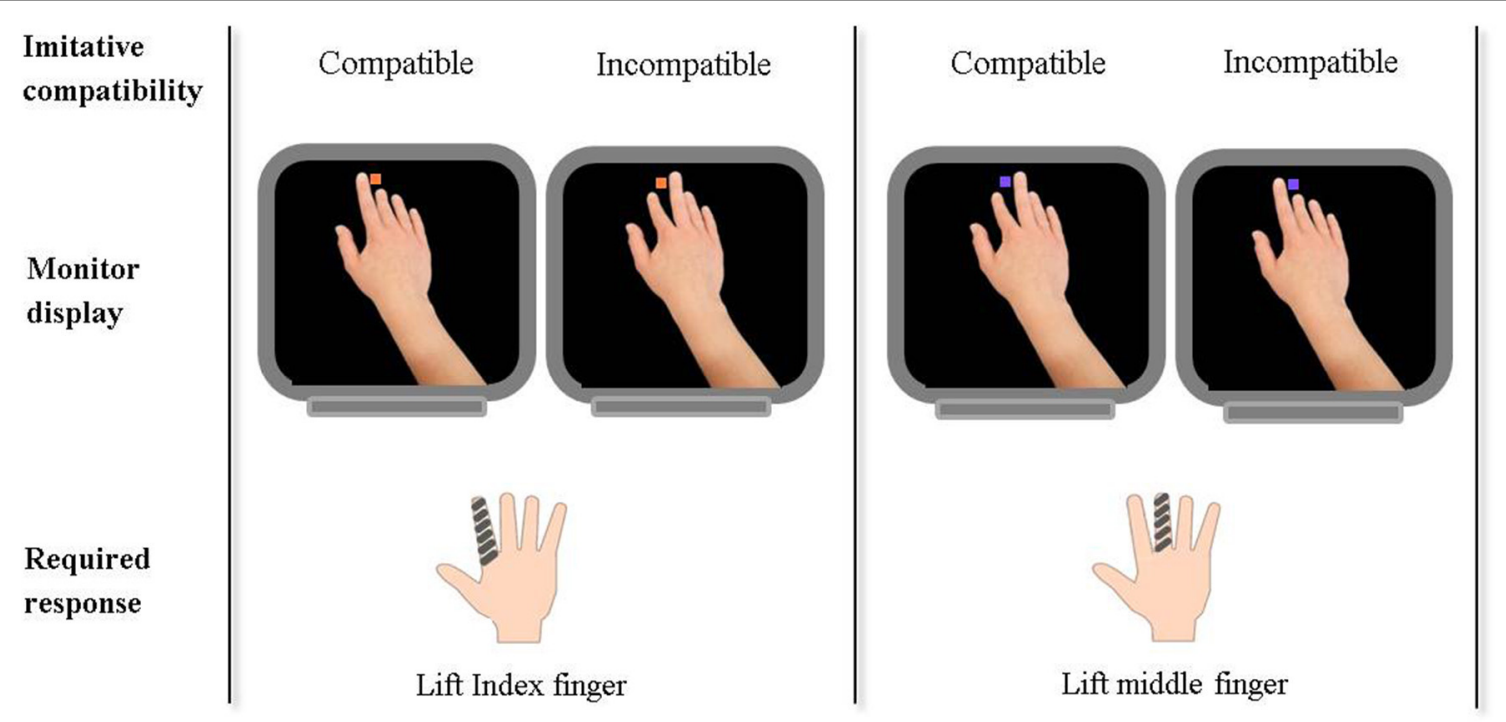

FIGURE 1 | Example of stimuli presented and participant responses required in a task to measure the control of imitation. The task: Participants are instructed to make either an index or middle finger lifting action in response to a colored cue (orange or purple square) presented on the monitor display. The cue is also accompanied by a task-irrelevant hand performing an index or middle finger lifting action. Thus, task-irrelevant stimuli can be either imitatively compatible or incompatible with the required finger response. An index of self-other control is calculated by subtracting response times on compatible trials from those on incompatible trials. Imitative compatibility of the task-irrelevant stimuli with the required finger lift response is also indicated for trials in which an orange square indicates lift index and a purple square indicates lift purple. imitation produces an enhancement of perspective-taking abilities (Santiesteban et al., 2012b). Moreover, priming prosocial attitudes enhances automatic imitation but not a non-imitative control process (Leighton et al., 2010; Cook and Bird, 2011) and engaging in more social interaction appears to improve other social abilities (Hogeveen and Obhi, 2012). Both of these examples support the enhancement of a common process involved in social functioning.

\section{A NEURAL BASIS FOR SELF-OTHER CONTROL}

As well as the medial prefrontal cortex (mPFC), the right temporoparietal junction (rTPJ), a brain region located at the intersection of the superior temporal sulcus and inferior parietal lobule, has attracted extensive research attention and has now been implicated in a wide range of social cognitive abilities, including judging agency, perspectivetaking, theory of mind and empathy (Decety and Sommerville, 2003; Decety and Lamm, 2007; van Overwalle, 2009; Sperduti et al., 2011). A series of studies by Brass et al. (2001, 2005, 2009) and Spengler et al. (2009a,b) utilized functional magnetic resonance imaging
(fMRI) to localize the neural areas related to the control of imitation to the rTPJ and mPFC. These studies suggest that the mPFC and/or the TPJ may be the neural substrate of self-other control.

Further, causal evidence for the role of the rTPJ in self-other control is derived from studies measuring the effects of magnetic or electric stimulation of this area. Disruptive repetitive transcranial magnetic stimulation (rTMS) of rTPJ has been shown to impair performance in both the control of imitation (Sowden and Catmur, 2013) and theory of mind (Costa et al., 2008; Young et al., 2010). Excitatory transcranial direct current stimulation (tDCS) enhanced imitative control and perspective-taking performance (Santiesteban et al., 2012a). The work of Santiesteban and colleagues is particularly noteworthy, as excitation of rTPJ enhanced self representations and inhibited representation of the other in the imitation inhibition task, but also enhanced other representations and inhibited self representations in the perspectivetaking task. This pattern of results is best explained by the up-regulation of a mechanism which facilitates the control of self and other representations. Similarly, acquired temporoparietal lesions have been associated with rare disorders such as asomatognosia, characterized by the misidentification of part of one's own body as belonging to another (Feinberg et al., 2010) and anosognosia, characterized by a denial or unawareness of a paralyzed limb (Ramachandran and Blakeslee, 1998).

Another competing idea is that the mPFC and rTPJ, rather than facilitating the control of competing representations of self and other, may in fact help to differentiate task-relevant from taskirrelevant representations (Nicolle et al., 2012; Cook, 2014). Indeed, there may be an interesting avenue for picking apart these two dimensions. However, at present it remains unclear how this mechanism may extend to a range of social cognitive abilities investigated to date in the self-other control literature, and how this may translate into a mechanism capable of explaining atypical social cognition.

\section{ATYPICAL SOCIAL COGNITIVE DEVELOPMENT}

Uncovering a common low-level mechanism for social cognition seems particularly useful when considering atypical social cognitive development. Mirror touch synaesthesia, in which the 
observation of touch or pain to others elicits an overt somatic sensation in the synaesthete's own body, is also associated with structural abnormalities in the TPJ and could be described as one example of a disorder of self-other control (Banissy and Ward, 2013; Holle et al., 2013).

Similarly, the ability to control neural representations of the self and of other people seems a central aspect of more common disorders of social cognition, such as autism and schizophrenia (Spengler et al., 2010b; Ferri et al., 2012). Several studies postulate atypical self-control in these disorders which impacts upon the attribution of agency to self and others in individuals with schizophrenia (Renes et al., 2013), and impairments in inhibiting imitation, theory of mind and perspective-taking in ASD (Lombardo et al., 2010, 2011; Spengler et al., 2010a,b). Lombardo et al. (2011) identified abnormalities in the recruitment of the rTPJ when making judgments requiring self-other differentiation in individuals with ASD relative to controls. Similarly, Spengler et al. (2010b) found that, in a sample of high functioning autistic individuals, increased imitation was associated with reduced theory of mind and decreased activity in areas typically required for self-other control. Despite varied terminology, including self-other "differentiation," "distinction," "switching" or "agency," all postulated processes appear to share a common feature of the "control" of shared representations.

Indeed, key aspects of the schizophrenia symptom profile can be explained by a deficit in self-other control. Identity and reality disturbances including hallucinations and delusions of persecutory control, disturbed consciousness and thought insertion exemplify a misattribution of self-generated, internal representations to others or the external world, highlighting a difficulty in managing representations of self and others (Frith, 1992; Allen et al., 2004, 2006; Jeannerod, 2009). Moreover, abnormal structure and function of the TPJ is reported in individuals at risk (Brüne et al., 2011), as well as suffering from schizophrenia (Benedetti et al., 2009; Lee et al., 2011; Das et al., 2012; de Achával et al., 2012; Koeda et al., 2013), relative to healthy controls. Diminished activation of this region has been associated with impaired social cognitive performance, in particular theory of mind and emotion processing domains (Benedetti et al., 2009; Lee et al., 2011; Das et al., 2012).

More recently it has been suggested that the impairments seen in ASD and schizophrenia can be characterized as a failure of top-down modulation of social behavior (Southgate and Hamilton, 2008; Cook and Bird, 2012; Cook et al., 2012; Wang and Hamilton, 2012). Of particular note, Cook and Bird (2012) found that the modulatory effects of priming pro-social attitudes on self-other control observed in neurotypical adults were absent in individuals with ASD. In the same vein, reduced fronto-temporal functional connectivity is now a well-established feature of schizophrenia and has been linked to diminished top-down modulatory control over social behavior (Allen et al., 2008; Cook et al., 2012).

\section{A NEUROCOGNITIVE MARKER FOR ATYPICAL SOCIAL COGNITION?}

Although we know little about the precise developmental trajectories for the neurocognitive deficits discussed, by highlighting a mechanism with the potential to explain many facets of social cognitive function researchers may be better equipped to advise on neurocognitive markers and possible interventions for common disorders of social cognition. Self-other control emerges as such a candidate neurocognitive mechanism. Future assessment of disorders of social cognition can benefit from the now widely used task of imitative control (Figure 1) as a robust behavioral index of self-other control which includes the requirement for online modulation of both self- and otherrepresentations in one task. Performance on imitative control tasks predicts performance across various domains of social cognition, and thus may provide a means to predict a pattern of atypical social development, in addition to measures of the structure and function of critical regions such as the rTPJ and mPFC. One may predict that individuals with autism or schizophrenia will be impaired at controlling imitative response tendencies, indicative of a deficit in self-other control.

This opinion piece has explored behavioral and neuroscientific evidence for self-other control as a candidate neurocognitive mechanism for social cognition. With advances in the field, a mechanism such as this may be crucial in identifying neurocognitive markers of atypical development and providing a therapeutic target to ameliorate the symptoms of atypical social development. Of particular promise from the application of such a mechanism is a unified account of the broad range of social functioning impairments associated with ASD and schizophrenia.

\section{ACKNOWLEDGMENTS}

The authors are supported by the Medical Research Council and wish to thank Dr. Geoffrey Bird for his constructive comments on a previous version of the manuscript.

\section{REFERENCES}

Allen, P., Freeman, D., Johns, L., and McGuire, P. (2006). Misattribution of self-generated speech in relation to hallucinatory proneness and delusional ideation in healthy volunteers. Schizophr. Res. 84, 281-288. doi: 10.1016/j.schres.2006. 01.021

Allen, P., Larøi, F., McGuire, P. K., and Aleman, A. (2008). The hallucinating brain: a review of structural and functional neuroimaging studies of hallucinations. Neurosci. Biobehav. Rev. 32, 175-191. doi: 10.1016/j.neubiorev.2007. 07.012

Allen, P. P., Johns, L. C., Fu, C. H., Broome, M. R., Vythelingum, G. N., and McGuire, P. K. (2004). Misattribution of external speech in patients with hallucinations and delusions. Schizophr. Res. 69, 277-287. doi: 10.1016/j.schres.2003. 09.008

Banissy, M. J., and Ward, J. (2013). Mechanisms of self-other representations and vicarious experiences of touch in mirror-touch synesthesia. Front. Hum. Neurosci. 7:112. doi: 10.3389/fnhum.2013. 00112

Benedetti, F., Bernasconi, A., Bosia, M., Cavallaro, R., Dallaspezia, S., Falini, A., et al. (2009). Functional and structural brain correlates of theory of mind and empathy deficits in schizophrenia. Schizophr. Res. 114, 154-160. doi: 10.1016/j.schres.2009.06.021

Brass, M., Bekkering, H., and Prinz, W. (2001). Movement observation affects movement execution in a simple response task. Acta Psychol. 106, 3-22. doi: 10.1016/S0001-6918(00) 00024-X

Brass, M., Bekkering, H., Wohlschläger, A., and Prinz, W. (2000). Compatibility between observed and executed finger movements: comparing symbolic, spatial, and imitative cues. Brain Cogn. 44, 124-143. doi: 10.1006/brcg.2000.1225

Brass, M., Derrfuss, J., and von Cramon, D. Y. (2005). The inhibition of imitative and overlearned responses: a functional double 
dissociation. Neuropsychologia 43, 89-98. doi: 10.1016/i.neuropsychologia.2004.06.018

Brass, M., and Heyes, C. (2005). Imitation: is cognitive neuroscience solving the correspondence problem? Trends Cogn. Sci. 9, 489-495. doi: 10.1016/j.tics.2005.08.007

Brass, M., Ruby, P., and Spengler, S. (2009). Inhibition of imitative behaviour and social cognition. Philos. Trans. R. Soc. B Biol. Sci. 364, 2359-2367. doi: 10.1098/rstb.2009.0066

Brass, M., and Spengler, S. (2008). "The inhibition of imitative behavior and the attribution of mental states," in Social Cognition: Development, Neuroscience and Autism, eds T. Striano and V. Reid (Oxford: Blackwell), 52-66.

Brüne, M., Özgürdal, S., Ansorge, N., von Reventlow, H. G., and Peters, S., Nicolas, V., et al. (2011). An fMRI study of "theory of mind" in at-risk states of psychosis: comparison with manifest schizophrenia and healthy controls. Neuroimage 55, 329-337. doi: 10.1016/j.neuroimage.2010. 12.018

Catmur, C., and Heyes, C. (2011). Time course analyses confirm independence of imitative and spatial compatibility. J. Exp. Psychol. Hum. Percept. Perform. 37, 409-421. doi: 10.1037/a00 19325

Chartrand, T. L., and Bargh, J. A. (1999). The chameleon effect: the perception-behavior link and social interaction. J. Pers. Soc. Psychol. 76, 893-910. doi: 10.1037/0022-3514.76.6.893

Cook, J., Barbalat, G., and Blakemore, S. J. (2012). Top-down modulation of the perception of other people in schizophrenia and autism. Front. Hum. Neurosci. 6:175. doi: 10.3389/fnhum.2012. 00175

Cook, J., and Bird, G. (2011). Social attitudes differentially modulate imitation in adolescents and adults. Exp. Brain Res. 211, 601-612. doi: 10.1007/s00221-011-2584-4

Cook, J. L. (2014). Task-relevance dependent gradients in medial prefrontal and temporoparietal cortices suggest solutions to paradoxes concerning self/other control. Neurosci. Biobehav. Rev. 42, 298-302. doi: 10.1016/j.neubiorev.2014.02.007

Cook, J. L., and Bird, G. (2012). Atypical social modulation of imitation in autism spectrum conditions. J. Autism Dev. Disord. 42, 1045-1051. doi: 10.1007/s10803-011-1341-7

Costa, A., Torriero, S., Oliveri, M., and Caltagirone, C. (2008). Prefrontal and temporo-parietal involvement in taking others' perspective: TMS evidence. Behav. Neurol. 19, 71-74. doi: $10.1155 / 2008 / 694632$

Das, P., Lagopoulos, J., Coulston, C. M., Henderson, A. F., and Malhi, G. S. (2012). Mentalizing impairment in schizophrenia: a functional MRI study. Schizophr. Res. 134, 158-164. doi: 10.1016/j.schres.2011.08.019

de Achával, D., Villarreal, M. F., Costanzo, E. Y., Douer, J., Castro, M. N., Mora, M. C., et al. (2012). Decreased activity in right-hemisphere structures involved in social cognition in siblings discordant for schizophrenia. Schizophr. Res. 134, 171-179. doi: 10.1016/j.schres.2011.11.010

Decety, J., and Grèzes, J. (2006). The power of simulation: imagining one's own and other's behavior. Brain Res. 1079, 4-14. doi: 10.1016/j.brainres.2005.12.115
Decety, J., and Lamm, C. (2007). The role of the right temporoparietal junction in social interaction: how low-level computational processes contribute to meta-cognition. Neuroscientist 13, 580-593. doi: $10.1177 / 1073858407304654$

Decety, J., and Sommerville, J. A. (2003). Shared representations between self and other: a social cognitive neuroscience view. Trends Cogn. Sci. 7, 527-533. doi: 10.1016/j.tics.2003. 10.004

di Pellegrino, G. D., Fadiga, L., Fogassi, L., Gallese, V., and Rizzolatti, G. (1992). Understanding motor events: a neurophysiological study. Exp. Brain Res. 91, 176-180. doi: 10.1007/ BF00230027

Feinberg, T. E., Venneri, A., Simone, A. M., Fan, Y., and Northoff, G. (2010). The neuroanatomy of asomatognosia and somatoparaphrenia. J. Neurol. Neurosurg. Psychiatry 81, 276-281. doi: 10.1136/jnnp.2009.188946

Ferri, F., Frassinetti, F., Mastrangelo, F., Salone, A., Ferro, F. M., and Gallese, V. (2012). Bodily self and schizophrenia: the loss of implicit self-body knowledge. Conscious. Cogn. 21, 1365-1374. doi: 10.1016/j.concog.2012.05.001

Frith, C. D. (1992). The Cognitive Neuropsychology of Schizophrenia. Hove: Psychology Press.

Gallese, V., Fadiga, L., Fogassi, L., and Rizzolatti, G. (1996). Action recognition in the premotor cortex. Brain 119, 593-609. doi: 10.1093/brain/119.2.593

Heyes, C. (2011). Automatic imitation. Psychol. Bull. 137, 463. doi: $10.1037 / \mathrm{a} 0022288$

Hogeveen, J., and Obhi, S. S. (2012). Social interaction enhances motor resonance for observed human actions. J. Neurosci. 32, 5984-5989. doi: 10.1523/JNEUROSCI.5938-11.2012

Holle, H., Banissy, M. J., and Ward, J. (2013). Functional and structural brain differences associated with mirror-touch synaesthesia. Neuroimage 83, 1041-1050. doi: 10.1016/j.neuroimage.2013.07.073

Iacoboni, M. (2009). Imitation, empathy, and mirror neurons. Annual Rev. Psychol. 60, 653-670. doi: 10.1146/annurev.psych.60.110707.163604

Jeannerod, M. (2009). The sense of agency and its disturbances in schizophrenia: a reappraisal. Exp. Brain Res. 192, 527-532. doi: 10.1007/s00221-0081533-3

Koeda, M., Takahashi, H., Matsuura, M., Asai, K., and Okubo, Y. (2013). Cerebral responses to vocal attractiveness and auditory hallucinations in schizophrenia: a functional MRI study. Front. Hum. Neurosci. 7:221. doi: 10.3389/fnhum.2013.00221

Lee, J., Quintana, J., Nori, P., and Green, M. F. (2011). Theory of mind in schizophrenia: exploring neural mechanisms of belief attribution. Soc. Neurosci. 6, 569-581. doi: 10.1080/17470919.2011. 620774

Leighton, J., Bird, G., Orsini, C., and Heyes, C. (2010). Social attitudes modulate automatic imitation. J. Exp. Soc. Psychol. 46, 905-910. doi: 10.1016/j.jesp.2010.07.001

Lombardo, M. V., Chakrabarti, B., Bullmore, E. T., and Baron-Cohen, S. (2011). Specialization of right temporo-parietal junction for mentalizing and its relation to social impairments in autism. Neuroimage 56, 1832-1838. doi: 10.1016/j.neuroimage.2011.02.067
Lombardo, M. V., Chakrabarti, B., Bullmore, E. T., Sadek, S. A., Pasco, G., Wheelwright, S. J., et al. (2010). Atypical neural selfrepresentation in autism. Brain 133, 611-624. doi: 10.1093/brain/awp306

Nicolle, A., Klein-Flügge, M. C., Hunt, L. T., Vlaev, I., Dolan, R. J., and Behrens, T. E. (2012). An agent independent axis for executed and modeled choice in medial prefrontal cortex. Neuron 75, 1114-1121. doi: 10.1016/j.neuron.2012.07.023

Obhi, S. S., and Hogeveen, J. (2013). The controlled imitation task: a new paradigm for studying self-other control. Peer J. 1:e161. doi: 10.7717/ peerj.161

Ramachandran, V. S., and Blakeslee, S. (1998). Phantoms in the Brain: Probing the Mysteries of the Human Mind. New York, NY: William Morrow.

Renes, R. A., Vermeulen, L., Kahn, R. S., Aarts, H., and van Haren, N. E. (2013). Abnormalities in the establishment of feeling of self-agency in schizophrenia. Schizophr. Res. 143, 50-54. doi: 10.1016/j.schres.2012.10.024

Santiesteban, I., Banissy, M. J., Catmur, C., and Bird, G. (2012a). Enhancing social ability by stimulating right temporoparietal junction. Curr. Biol. 22, 2274-2277. doi: 10.1016/j.cub.2012. 10.018

Santiesteban, I., White, S., Cook, J., Gilbert, S. J., Heyes, C., and Bird, G. (2012b). Training social cognition: from imitation to theory of mind. Cognition 122, 228-235. doi: 10.1016/j.cognition.2011.11.004

Southgate, V., and Hamilton, A. F. (2008). Unbroken mirrors: Challenging a theory of autism. Trends Cogn. Sci. 12, 225-229. doi: 10.1016/j.tics.2008.03.005

Sowden, S., and Catmur, C. (2013). The role of the right temporoparietal junction in the control of imitation. Cereb. Cortex. doi: 10.1093/cercor/ bht306. [Epub ahead of print].

Spengler, S., Bird, G., and Brass, M. (2010a). Hyperimitation of actions is related to reduced understanding of others' minds in autism spectrum conditions. Biol. Psychiatry 68, 1148-1155. doi: 10.1016/j.biopsych.2010.09.017

Spengler, S., von Cramon, D. Y., and Brass, M. (2009a). Control of shared representations relies on key processes involved in mental state attribution. Hum. Brain Mapp. 30, 3704-3718. doi: 10.1002/hbm.20800

Spengler, S., von Cramon, D. Y., and Brass, M. (2009b). Was it me or was it you? How the sense of agency originates from ideomotor learning revealed by fMRI. Neuroimage 46, 290-298. doi: 10.1016/j.neuroimage.2009.01.047

Spengler, S., von Cramon, D. Y., and Brass, M. (2010b). Resisting motor mimicry: control of imitation involves processes central to social cognition in patients with frontal and temporo-parietal lesions. Soc. Neurosci. 5, 401-416. doi: 10.1080/17470911003687905

Sperduti, M., Delaveau, P., Fossati, P., and Nadel, J. (2011). Different brain structures related to selfand external-agency attribution: a brief review and meta-analysis. Brain Struct. Funct. 216, 151-157. doi: 10.1007/s00429-010-0298-1

van Overwalle, F. (2009). Social cognition and the brain: A meta-analysis. Hum. Brain Mapp. 30 829-858. doi: 10.1002/hbm.20547 
Wang, Y., and Hamilton, A. F. (2012). Social top-down response modulation (STORM): a model of the control of mimicry in social interaction. Front. Hum. Neurosci. 6:153. doi: 10.3389/fnhum.2012.00153

Young, L., Camprodon, J. A., Hauser, M., PascualLeone, A., and Saxe, R. (2010). Disruption of the right temporoparietal junction with transcranial magnetic stimulation reduces the role of beliefs in moral judgments. Proc. Natl. Acad. Sci. U.S.A.107, 6753-6758. doi: 10.1073/pnas.0914826107
Conflict of Interest Statement: The authors declare that the research was conducted in the absence of any commercial or financial relationships that could be construed as a potential conflict of interest.

Received: 15 April 2014; accepted: 17 September 2014; published online: 08 October 2014.

Citation: Sowden S and Shah P (2014) Self-other control: a candidate mechanism for social cognitive function. Front. Hum. Neurosci. 8:789. doi: 10.3389/fnhum. 2014.00789
This article was submitted to the journal Frontiers in Human Neuroscience.

Copyright (c) 2014 Sowden and Shah. This is an openaccess article distributed under the terms of the Creative Commons Attribution License (CC BY). The use, distribution or reproduction in other forums is permitted, provided the original author(s) or licensor are credited and that the original publication in this journal is cited, in accordance with accepted academic practice. No use, distribution or reproduction is permitted which does not comply with these terms. 